\title{
Male Monsters Still Stalk, Yet More Violent: A Comparative Analysis of Original Slasher Films and Their Remakes
}

\author{
Víctor Hernández-Santaolalla ${ }^{1}$ (D) Irene Raya ${ }^{2}$ (D)
}

Accepted: 12 December 2021 / Published online: 30 December 2021

(c) The Author(s) 2021

\begin{abstract}
Since its origins in the mid-1970s, the slasher has been defined as a subgenre of horror in which a serial or mass killer stalks and massacres middle-class youngsters, and preferably attractive young women, using cutting weapons or projectiles. In that regard, the twenty-first century has seen a revival of the slasher, combining the release of original movies with remakes of classic films, adapting the traditional plots to the current context. In this paper, a comparative content analysis is performed on 13 slasher films made during the 1970s and the 1980s and 13 remakes premiered in the new millennium, focusing on the differences stemming from the adaptation of the latter to the new sociocultural context. The results indicate that, although there have been a number of changes, such as higher doses of explicit violence and profanity and in the fight responses of the victims, most of the subgenre's defining traits have remained intact, whereas others, such as those relating to the defining traits of the victims, should be questioned. The limited differences found between the original films and the remakes provide the basis for drawing interesting conclusions about the subgenre itself, as well as to raise discussions about the different contexts of production and reception.
\end{abstract}

Keywords Slasher film $\cdot$ Violence $\cdot$ Sex $\cdot$ Final girl $\cdot$ Content analysis

Víctor Hernández-Santaolalla

vhsantaolalla@us.es

Irene Raya

iraya@us.es

1 Faculty of Communication, Universidad de Sevilla (Room B6), Av. Américo Vespucio, n/n, 41092 Seville, Spain

2 Faculty of Communication, Universidad de Sevilla (Room H3), Av. Américo Vespucio, n/n, 41092 Seville, Spain 


\section{Introduction}

In 1974, the release of The Texas Chainsaw Massacre (Tobe Hooper, 1974) and Black Christmas (Bob Clark, 1974) marked the advent of slasher films, one of the most prolific subgenres of the horror film genre. Four years on, John Carpenter's Halloween would define its characteristics once and for all: a serial or mass killer dedicated to stalking and massacring youngsters, mostly middle-class girls, employing to this end primarily blunt or sharp weapons like knives, axes, saws or harpoons (HernándezSantaolalla, 2019; Keisner, 2008; Molitor \& Sapolsky, 1993; Pérez Ochando, 2016; Petridis, 2014). Although the Italian giallo and films like Thirteen Women (George Archainbaud, 1932), Peeping Tom (Michael Powell, 1960), Psycho (Alfred Hitchcock, 1960) and The Last House on the Left (Wes Craven, 1972) could be understood as its precursors, it was the three aforementioned films that would establish the subgenre in its own right. Thenceforth, it would become highly popular throughout the 1970s and the 1980s, until entering into decline in the following decades once the novelty had worn off. Later on, in the twentieth-first century, slasher films would make a comeback in the shape of remakes of the subgenre's classics.

In this paper a comparative content analysis is performed on these films and their original versions. Specifically, aspects such as the violent and/or sexual content of the scenes, as well as the characteristics of the victims or the killers were analyzed. The remakes seek to recover the original narratives, but at the same time updating them according to the new specific context of production. In this sense, the comparison between the classic films and the new versions is interesting because it would provide an insight into how the subgenre, according to the sociocultural context, has evolved over the years. In other words, similar to the study of film adaptations across countries, the analysis of remakes made in a different temporal context than the original films would provide information on how ideological and cultural changes permeate the process of creating these revisions (Wee, 2014, p. 1). Especially considering that_-as "collective nightmare" (Wood, 2003, p. 70)__horror films seem to be particularly suited to reflect the concerns and traumas of societies (Ryan \& Kellner, 1988; Wee, 2014), while the slasher subgenre in particular has been understood as a moralizing narrative that indicates which behaviors are socially accepted and which should be punished.

As regards the structure of the article, after a first part in which the characteristics of the slasher, the periods and the relevance of the film remake for the subgenre are pointed out, the empirical work deals with three fundamental aspects: how the killers and victims are represented, how the sexual and violent content is manifested, and how the deaths are carried out. In this way, the original-remake comparative analysis of these issues will allow us to know, among other questions, how the social acceptance of certain behaviors, the doses of violence and sex, or the stereotyping in terms of gender or race has evolved. 


\section{The Characteristics of the Slasher}

Slashers have traditionally featured mass killers who a priori slay everyone in their path. In this respect, the killer is usually a man, an incredibly strong and practically indestructible human monster (Kvaran, 2016; Rockoff, 2002; Wee, 2006) against whom the final girl, the only person capable of anticipating the catastrophe and confronting him in the final moments of the film, either to make good her escape or to destroy him, has to pit her wits (Clover, 2015). Thus, even though slasher films are not restricted, at least in theory, to a pre-established gender differentiation, it has traditionally been noted that if the killer is a man, his victims, including the survivors, are mostly women (Clover, 2015; Kvaran, 2016; Trencansky, 2001; Weaver et al. 2015). Nevertheless, the content analyses performed by Cowan and O'Brien (1990) and Weaver III (1991) confronts this idea, revealing that there were not statistically significant differences in the number of victims in terms of their sex. In this respect, and according to these data, it is possible that the traditionally perceived differences between male and female characters may not have so much to do with the number of victims as with the way and context in which they are murdered, with the death of the female victims being shown in more detail. Thus, as a prior step to the murder per se, the psycho killer stalks his/her victim, sharing his/her point of view with the audience who assume "the (uncomfortable and/or exciting) role of an accomplice to an obsessive, sadistic voyeur" (Forman-Brunell, 2002, p. 257). This perspective would ultimately serve to counteract the audience's previous dissociation and lack of empathy with the monster (Rubin, 2000).

Additionally, the slasher subgenre was originally understood as a sort of cautionary tale warning the young about the dangers of violating the moral order, particularly with respect to sexual relations, but also regarding drug consumption, among other things. This tendency to chastise premarital sex has led to final girls being identified as virgins or at least as sexually unavailable (Keisner, 2008; Wee, 2006; Welsh, 2010). Nonetheless, these films seldom explicitly refer to the characters' virginity (Weaver et al. 2015). The reason behind this may be the fact that these survivors either do not exhibit any type of sexual behavior in the plot or this is less explicit in comparison with that of the victims. Furthermore, they never usually appear either partially or completely naked on screen. For Weaver et al. (2015), while certain suggestive behaviors-such as kissing a boyfriend or girlfriend or wearing more provocative clothes_are valid mechanisms for engaging teen audiences, others are publically condemned. On that subject, the results of the content analysis of Wellman et al. (2021) revealed that, with regard to female characters, sexual behavior was related to the probability of dying and suffering higher doses of violence. In this regard, while heroines may appear sexually dressed, they do not usually engage in sexual acts. Therefore, they conclude that "slasher films disseminate messages that equate femininity with purity and female sexuality with sin that is punishable with horrific violence" (p. 676), thus potentially contributing to perpetuate and reinforce these stereotypical gender roles.

So, apart from this lack of licentiousness, the final girls-and boys-are no different from the rest of the victims as regards their age, sexual orientation, 
race, way of dressing or relationship status. Nonetheless, they tend to possess an androgynous nature (Weaver et al., 2015; Wellman et al., 2021), which has led Clover (2005) to define them as "boyish" (p. 204). In other words, the characteristics usually attributed to their sex are practically conspicuous by their absence, an aspect also shared by the final boys, whose androgyny prevents them from being shown as truly masculine. These final boys always play secondary roles with respect to their female cast members. Accordingly, although there can be a sole female survivor, it is difficult to find examples of a boy who manages to pull through. In other words, while the final girl is shown to be not only a recurring but a fundamental character in these films, the existence of the final boy is much more anecdotal. It is the final girls who have the ability to check the monster, for which reason they have to adopt the "male gaze" (Mulvey, 1999), ceasing to be the observed to become the observers and wielding a phallic weapon to survive the bloodbath. In other words, to emerge victorious they have to play an active role traditionally attributed to men (Christensen, 2016; Clover, 2015; Connelly, 2007; Trencansky, 2001).

\section{Slasher Film Periods}

Petridis (2014) has established three main periods. The first is known as the classic period from the subgenre's advent to the end ofthe 1980s; a particularly conservative period overshadowed by Ronald Reagan's twopresidencies. According to Vera Dika, it was precisely the social and economic transition between the 1970s and the 1980s which influenced the emergence and evolution of slasher (cited in Kvaran 2016 , p. 955). The optimism and prosperity that many people nostalgically associate with the Reaganian era was only felt by one sector of the population, while for the other "the decade would be filled with financial anxiety and economic pessimism". This double vision was also portrayed in cinema entertainment. Thus, in the face of those films that offered an "optimistic narrative, slasher films can be seen as a counterpoint to the dominant ideology, one that through incredibly violent allegory represented the failings of the modern economy" (p. 955).

However, the subgenre was soon plunged into crisis as a result of its considerable lack of creativity, which would subsequently lead to its reformulation in the 1990s with the postmodern or post-slasher film period, beginning with Wes Craven's New Nightmare (1994) and Scream (1996). This second period was characterized by self-centeredness, intertextuality and self-awareness (Wee, 2006), resulting in the recuperation of the subgenre's clichés to parody or even subvert them. At the end of the 1990s, however, this attempt at revamping the subgenre ran out of steam, leading to the current period, i.e. that of the neo-slasher. Original films like Hatchet (Adam Green, 2006) and Happy Death Day (Christopher B. Landon, 2017) were premiered along with remakes of the subgenre's classics. As to the latter, these included new versions of The Texas Chainsaw Massacre (Marcus Nispel, 2003) or Halloween (Rob Zombie, 2007); a cinema that looked back nostalgically on the United States' past, in the wake of the 9/11 terrorist attacks (Wetmore, 2012). Likewise, the intention of other filmmakers was to recuperate the seminal slashers 
(not being remakes), such as the crossover Freddy vs. Jason (Ronny Yu, 2003). At the same time, previous sagas like Scream with Scream 4 (Wes Craven, 2011) and Halloween (David Gordon Green, 2018) were given continuity. Finally, during this period the slasher subgenre was also adapted for television, with series like Scream (MTV, 2015-), Scream Queens (Fox, 2015-2016) and Slasher (Super Channel, 2016; Netflix, 2017-).

\section{Remake in the Slasher Subgenre}

The production of remakes is a successful trend in the film industry, insofar as it has allowed for the reuse of characters, locations and arguments familiar to the public, while updating the original storyline. Moine (2007) describes three approaches from which the remake phenomenon can be analyzed: from a production approach, a habitual technique in Hollywood; from a representation approach, to wit, as a reformulation of a film proposal in another cultural, ideological, narrative, aesthetic or generic context; and from a reception and interpretation approach. From an economic viewpoint, different studies have highlighted how remakes, as with sequels, are seen by the critics as financial formats that undermine cinematographic originality (Berliner, 2001; Greenberg, 1991; Jess-Cooke \& Verevis, 2010; Verevis, 2006), being considered industrial products of proven profitability that "are consistently thought to provide suitable models, and something of a financial guarantee" (Verevis, 2006, p. 3). This film production practice usually works within the slasher, since "horror films are also a safe economic decision to make because of their relatively inexpensive production budgets and predictable box office draw" (Lizardi, 2010, p. 114).

Notwithstanding this, the perspective shifts when analyzing remakes as representations with the potential to highlight new social concerns, plus aesthetic, narrative and technological changes that help to understand both the message itself and the reality in which it is framed. The purpose of remakes is not only to alter settings by relocating and adapting stories to other geographical and cultural contexts as transnational remakes (Durham, 1998; Fernández Labayen \& Martín Morán, 2017; Moine, 2007), but also to alter the temporal context by setting them in a different historical period. Along these lines, comparative studies like that conducted by Nelson (2010) refute the allegation that remakes are a symptom of creative burnout. By comparing Carpenter's original Halloween with Rob Zombie's, the author reveals the complex transformational tools with which the US film industry appropriates the content of old films to reflect current social circumstances and policies through the new versions. Also focusing on comparative studies between original slashers and their remakes, Lizardi (2010) examines how these films express contemporary social concerns, and points out how "cultural implications of slasher remakes include hyperemphasis of the originals' hegemony and misogyny" (2010, p. 113).

Analyzed as discourses, remakes are linked to the concept of intertextuality in a broad sense of the word (Moine, 2007; Quaresima, 2002; Stam, 2000; Verevis, 2006); that is, a relationship of copresence (Genette, 1997, p. 1) is established between the original cinematic text and the remake when reproducing elements in 
the new production that recall to the first version. This is so because they are determined by the audience's expectations and knowledge of the original product, insofar as they include references and allusions to it in a sort of nostalgic strategy that, while recuperating the basic storyline, constructs a different one. This referentiality is omnipresent in the horror subgenre, so inclined to expanding and reinventing itself, this being especially evident in the proliferation of teen slasher films, which began to appear in the middle of the 1990 s with the Scream saga (Wee, 2005). More often than not, the objective of these new versions is not to imitate the original films, but to reinvent the primal concept, fairly similar to the term "analogy" normally employed when describing adaptations (Wagner, 1975). This is so because a storyline diverging from the original is developed on the basis of the same initial elements, thus entering the terrain of reimagining.

In short, this study departs from the notion that the new versions of original films seek to update - if not to reinvent - the plot, which involves catering to the particularities of the sociocultural context in which they are produced. However, slashers present such defined characteristics that any innovation is restricted by the nature of the subgenre. Thus, the objective of this article is to identify the differences between the original slasher films and their contemporary versions to determine how the subgenre has evolved, if so. In particular, the following research question is proposed:

RQ1. Has the slasher subgenre evolved in terms of the use of violence and sex and the characteristics of the characters involved?

In this regard, the comparative study is relevant to the extent that the results obtained will allow for discussions not only regarding the nature of the subgenre itself, but also in relation to the contexts of production and reception of the films.

\section{Methods}

To meet the research objective and to answer the questions posed above, a quantitative methodology was employed. Thus, in accordance with previous studies such as those performed by Cowan and O'Brien (1990), Weaver III (1991), Molitor and Sapolsky (1993), Welsh $(2009,2010)$ and Weaver et al. (2015), a content analysis was conducted on films belonging to the slasher subgenre.

\section{Sample}

A total of 26 films, 13 originals released between 1974 and 1986-the year in which the slasher seemed to be nearing its end (Rockoff, 2002)__and another 13 new versions were analyzed. Specifically, the corpus was selected following three criteria: (1) the original version should be a slasher of the classic period (Petridis, 2014)(first instalment in the case of film sagas), (2) which should have a remake, and (3) all the films should havebeen released in theaters. Moreover, the films were chosen following a broad definition of the subgenre: a serial or mass murderer who 
stalks and kills mainly young people using sharp weapons. In this sense, the original films and remakes of The Hills Have Eyes, Maniac and The Hitcher were also analyzed, because, although they do not always appear in slasher film listings, authors such as Clayton $(2015,2020)$ include them within the subgenre.

The complete list of the films analyzed can be found in Table 1.

\section{Variables}

The analysis sheet and codebook, developed on the basis of previous research conducted by Cowan and O'Brien (1990), Gilpatric (2010), Molitor and Sapolsky (1993), Weaver III (1991), Weaver et al. (2015) and Welsh (2009, 2010), was divided into three main sections: violent and/or sex scenes, killers and victims and deaths.

Scenes: (a) duration (in seconds), (b) location, (c) type_-violent (verbal or physical aggression), sex (consensual) or violent and sex (a mix of the two above

Table 1 Corpus of film analysed

\begin{tabular}{|c|c|c|}
\hline Film & Director & Year \\
\hline Black Christmas & Bob Clark & 1974 \\
\hline Black Christmas & Glen Morgan & 2006 \\
\hline The Texas Chain Saw Massacre & Tobe Hooper & 1974 \\
\hline The Texas Chainsaw Massacre & Marcus Nispel & 2003 \\
\hline The Hills Have Eyes & Wes Craven & 1977 \\
\hline The Hills Have Eyes & Alexandre Aja & 2006 \\
\hline Halloween & John Carpenter & 1978 \\
\hline Halloween & Rob Zombie & 2007 \\
\hline The Toolbox Murders & Dennis Donnelly & 1978 \\
\hline Toolbox Murders & Tobe Hooper & 2004 \\
\hline When a Stranger Calls & Fred Walton & 1979 \\
\hline When a Stranger Calls & Simon West & 2006 \\
\hline Friday the 13 th & Sean S. Cunningham & 1980 \\
\hline Friday the 13th & Marcus Nispel & 2009 \\
\hline Prom Night & Paul Lynch & 1980 \\
\hline Prom Night & Nelson McCormick & 2008 \\
\hline Maniac & William Lustig & 1980 \\
\hline Maniac & Franck Khalfoun & 2012 \\
\hline My Bloody Valentine & George Mihalka & 1981 \\
\hline My Bloody Valentine & Patrick Lussier & 2009 \\
\hline The House on Sorority Row & Mark Rosman & 1983 \\
\hline Sorority Row & Stewart Hendler & 2009 \\
\hline A Nightmare on Elm Street & Wes Craven & 1984 \\
\hline A Nightmare on Elm Street & Samuel Bayer & 2010 \\
\hline The Hitcher & Robert Harmon & 1986 \\
\hline The Hitcher & Dave Meyers & 2007 \\
\hline
\end{tabular}


or sexual abuse or rape) —_ and (d) the characters involved — - final girl or final boy (if they have an important role in the story and survive), killer (the antagonist of the story who stalks and attacks the victims), and another male or female character- - It should be noted that violence against animals and the injuries that the victims might have sustained by accident were not taken into account (Welsh, 2009, 2010). Furthermore, the identification of the scenes was based on Robert McKee's definition: "an action through conflict in a more or less continuous time and space that converts the value-laden condition of a character's life into at least one value with a perceptible degree of significance" (2010, p. 35).

Killers and victims: (a) age, (b) sex, (c) race, (d) relationship status, (e) sexual orientation, (f) virginity_ _ for the latter three only if it is explicitly represented in the film——, $(\mathrm{g})$ depicted sexual behavior_— none; implied, not depicted; only kisses; mild (sexual approach, but not significant) and significant (oral sex or coitus) — _ and (h) consumption of drugs and/or alcohol were analyzed. In relation to the race, although the classification of the US Census Bureau was adapted, in accordance with Gilpatric (2010), the 'Hispanic or Latin' category was included, in line with the findings provided by the bureau itself. Additionally, with respect to the victims (i) whether or not some type of nudity is depicted, (j) the use of obscene language, and $(\mathrm{k})$ the presence of agentic behavior — the victim's choice to fight, to flee or to freeze in the presence of the killer — were also examined.

Deaths: (a) whether or not they are shown on screen, (b) sex of the mortal victim, (c) weapon employed and (d) duration (in seconds). All the bodies that appeared were counted as dead, regardless of whether their identity was known. In this sense, the scenes in which the murders were committed were, in turn, violent scenes, but the aspects analyzed were different. While violent scenes define some kind of physical aggression, they do not necessarily involve death or the presence of the killer. In contrast, death scenes necessarily incorporate the death of a character, considering the murder weapon as well as the explicitness of the death (onscreen/off screen).

\section{Content Coders}

Coding was carried out by two coders. The coders watched all the films and subsequently analyzed half of the sample, which was randomly assigned. However, as a preliminary step to the analysis, a coding test was performed on a sample of two films, one original and one remake, also randomly selected. According to Krippendorff's alpha, the intercoder reliability reached was 0.821 for the violent and/or sex scenes analysis, 0,929 for the analysis of the killers, 0.946 for the analysis of the victims, and 0,896 for the analysis of the murders committed. Bearing in mind the difficulties inherent to thematic units (Krippendorff, 2004, pp. 108-109), these are all very high scores. The consistency of the measures of the duration of the scenes was analyzed according to Pearson's correlation. A coefficient of $0.895(p<0.001)$ for the violent and/or sex scenes duration, and $0.871(p<0.001)$ for the murders duration were obtained. All data were analyzed using the IBM SPSS Statistics 25. 


\section{Results}

A general analysis of the films in the corpus revealed that the new versions include higher doses of violence and more murders (Table 2). In relation to the violent scenes, for example, they vary increasing from 4 to 10 scenes included in the original versions of Black Christmas and Halloween, respectively, to 13 and 22 in the recent ones. For its parts, moving on to the number of deaths, these jump from 3 in the original version of When a Stranger Calls to 6 in the remake, while in relation to My Bloody Valentine the number increases from 16 in the 1981 film to 33 in the version of the 2009. In this regard, there are three variables in which statistically significant differences are found, according to the two-sample t-test: violent scenes $\left(\mathrm{t}_{(24)}=-2.78, p<0.02\right)$, the death toll $\left(\mathrm{t}_{(24)}=-2.29, p<0.04\right)$ and the number of victims $\left(\mathrm{t}_{(24)}=-2.56, p<0.03\right)$. However, this is not so as regards the survivors, there being an equal number of final girls and final boys in the originals and their new versions.

\section{Violent and/or Sex Scenes}

Of the 328 scenes analyzed $87.20 \%$ are violent, $7.62 \%$ contain consensual sex and the rest a combination of both. In this regards, by and large it can be observed how the new versions include a greater number of violent or sex scenes; a growing trend that changes in scenes combining sex and violence. A paradigmatic example of the latter category can be found in My Bloody Valentine (George Mihalka 1981), whose opening sequence shows a couple having a sexual encounter inside a mine. A little over a minute and a half into the scene, the man dressed as a miner, who remains clothed at all times, ends up impaling the half-naked girl-presented from the start as an erotic lure for the audience-with a pickaxe.

Concerning the characters involved in each one of the scenes (Table 3), the killer plays a leading role when these contain violence. Moreover, neither the murderer nor the final girl and/or the final boy usually participate when the scenes have an exclusively sexual nature. In this regard, no statistically significant differences were found in the participation of these characters in such scenes between the original

Table 2 General analysis of the original films and their new versions

\begin{tabular}{llllrl}
\hline & \multicolumn{2}{l}{ Original } & & \multicolumn{2}{l}{ New version } \\
\cline { 2 - 3 } \cline { 5 - 6 } & $\mathrm{M}$ & $\mathrm{SD}$ & & $\mathrm{M}$ & $\mathrm{SD}$ \\
\hline Violent scenes & 8.77 & 3.56 & & 13.31 & 4.70 \\
Sex scenes & 0.62 & 0.65 & & 1.23 & 1.01 \\
Sex and violent scenes & 0.85 & 0.99 & & 0.46 & 0.66 \\
Deaths & 8.08 & 3.55 & & 13.23 & 7.31 \\
Killers & 1.38 & 0.65 & & 1.46 & 0.88 \\
Victims & 8.15 & 2.88 & & 13.85 & 7.49 \\
Final girls & 0.92 & 0.28 & & 1.15 & 0.69 \\
Final boys & 0.38 & 0.65 & & 0.46 & 0.66 \\
\hline
\end{tabular}


Table 3 Characters involved in violent and/or sex scenes (\%)

\begin{tabular}{|c|c|c|c|c|c|c|}
\hline & \multicolumn{2}{|l|}{ Violent } & \multicolumn{2}{|l|}{ Sex } & \multicolumn{2}{|c|}{ Violent and sex } \\
\hline & Original & New version & Original & New version & Original & New version \\
\hline Final girl & 35.09 & 40.70 & 0.00 & 11.76 & 36.36 & 50.00 \\
\hline Final boy & 12.28 & 13.37 & 0.00 & 11.76 & 9.09 & 0.00 \\
\hline Other female character & 40.35 & 42.44 & 100.00 & 82.35 & 63.64 & 50.00 \\
\hline Other male character & 40.35 & 49.42 & 87.50 & 82.35 & 54.55 & 50.00 \\
\hline Killer & 89.47 & 88.37 & 0.00 & 17.65 & 90.91 & 100.00 \\
\hline Total & 114 & 172 & 8 & 17 & 11 & 6 \\
\hline
\end{tabular}

films and the remakes. However, a more in-depth study reveals how the new versions include exclusively sexual scenes where the final girls/boys or the killers participate, in opposition to the original films. Specifically, in the remakes of The Hitcher and Sorority Row the final girls intimate with their respective boyfriends, who in the latter case are also revealed as the killers.

Nevertheless, it is different when violence and sex are mixed. In these scenes, the killer does have a leading role in both film versions, as he/she is responsible for the violence of the moment. However, while the final girl can play an important role in these scenes, the final boys remain practically absent. In this regard, two interesting examples can be found in the original versions of Prom Night and My Bloody Valentine. In both, the final girl suffers an episode of sexual harassment in public situations in which male characters are publicly confronted to defend their possession over the female character.

Furthermore, in some scenes of the new versions the final girl suffers an attempt of sexual abuse by the killer but in a much more private environment. In the case of The Hitcher, Grace is cornered by the killer in her own bed (during the struggle he tells her he is getting "horny"), while the whole plot of the remake of A Nightmare on Elm Street revolves around the sexual abuse that some children have experienced from Freddy Krueger (i.e., in one of his dreams, Freddy licks Nancy's face, reminding her of child abuse).

Regarding this sexual abuse of the final girl, there is a relevant scene in The Hills Have Eyes. In both the 1977 and 2006 versions, almost halfway through the film, Pluto, one of the mutants, after entering the family caravan, prepares to rape Brenda, the final girl. However, his intention is frustrated by Mars, in the first version, and by Lizard, in the second one, who reproaches Pluto for the fact that it is necessary to be a man to commit this type of act. In this way, it is the newcomer who prepares to carry out the rape. The difference is that, although in the first case the rape is not explicit and there is even doubt that it will be carried out, in the remake one can see how Lizard unbuttons her pants and changes Brenda's position. Later, the camera focuses on Pluto looking at the baby, while in the background Lizard moves his hip in time, howling with pleasure as his victim screams in despair.

Lastly, as to the duration in seconds of each one of the violent and/or sex scenes in the original films and their new versions, there are no significant differences 
according to the two-sample $t$ test assuming equal variances (although data in Table 4 show a disparity in the average number of seconds); something that would coincide with the high values of some standard deviations.

\section{Characteristics of the Victims}

Of the 263 victims figuring in the sample, $50.57 \%$ are women (Table 5). In other words, the number of male and female victims is practically identical, there being no statistically significant differences in this respect. Nonetheless, it can be observed how there are slightly more male victims in the new versions than in the original films. As regards the age variable, there are no statistically significant differences according to the chi-square test. However, considering the absolute frequency of appearance, some changes can be discerned in certain films. If in the original slashers, the victims are mostly young adults, followed by teenagers, in the new versions the different age groups are more equally represented, there being more middle-aged than teenage victims. An example of this is Prom Night. Whereas in the 1980 original there is only one middle-aged victim versus six teenagers, in the 2008 version, although there is only one teenage victim less, there are two young adult and six middle-aged victims.

This change is related to the appearance of a greater number of victims in the new versions, including mainly adults who appear for a fairly short time on screen and whose main role seems to increase the death counter. These are the cases of the police officers who record the scene at the beginning and the end of The Texas Chainsaw Massacre, the health care workers in Black Christmas, or the police officers and staff members of psychiatric hospital on Rob Zombie's Halloween — in which Michael Myers, as opposed to the original film, also ends the life of the Strode couple. It is significant, in this respect, how these new versions, as opposed to the original ones, include various deaths of domestic workers and cleaners, generally of Latino origin, as exemplified by the cases of Prom Night, My Bloody Valentine or When a Stranger Calls. Indeed, there seems to be an occupational link between the Hispanic or Latin victims, who are engaged in menial work when they are women and work as policemen or guards when they are male.

In this line, with respect to race, the new versions include non-white victims, although they are still a minority and play secondary roles, at least compared to the prominence of white characters. For instance, in the new version of Prom Night, Lisa, the best friend of Donna, the final girl, is a black teenager who plays an important role until her death. In Sorority Row, for its part, Claire, a young

Table 4 Duration in seconds according to the scenes and the type of film

\begin{tabular}{|c|c|c|c|c|c|c|}
\hline & \multicolumn{2}{|l|}{ Violent } & \multicolumn{2}{|l|}{ Sex } & \multicolumn{2}{|c|}{ Violent and sex } \\
\hline & Original & New version & Original & New version & Original & New version \\
\hline$M$ & 96.37 & 83.04 & 57.13 & 35.76 & 172.64 & 98.67 \\
\hline$S D$ & 101.60 & 100.68 & 43.73 & 21.97 & 109.00 & 54.15 \\
\hline
\end{tabular}


Table 5 Characteristics of the victims (\%)

\begin{tabular}{|c|c|c|c|}
\hline & Original & New version & Total \\
\hline \multicolumn{4}{|l|}{ Gender } \\
\hline Female & 57.43 & 46.30 & 50.57 \\
\hline Male & 42.57 & 53.70 & 49.43 \\
\hline \multicolumn{4}{|l|}{ Age } \\
\hline Child & 3.96 & 5.56 & 4.94 \\
\hline Teenager & 19.80 & 17.28 & 18.25 \\
\hline Young adult & 53.47 & 40.12 & 45.25 \\
\hline Middle age & 16.83 & 31.48 & 25.86 \\
\hline Older adult & 5.94 & 5.56 & 5.70 \\
\hline \multicolumn{4}{|l|}{ Race } \\
\hline White & 100.0 & 90.1 & 93.9 \\
\hline Black or African American & 0.0 & 3.7 & 2.3 \\
\hline Asian & 0.0 & 1.9 & 1.1 \\
\hline Hispanic or Latino & 0.0 & 4.3 & 2.7 \\
\hline \multicolumn{4}{|l|}{ Relationship status } \\
\hline Single & 8.9 & 5.6 & 6.8 \\
\hline Casual partner & 10.9 & 4.9 & 7.2 \\
\hline Serious partner & 24.8 & 18.5 & 20.9 \\
\hline Married/Common-law partner & 6.9 & 13.6 & 11.0 \\
\hline Undisclosed/Unknown & 41.6 & 52.5 & 48.3 \\
\hline Other & 6.9 & 4.9 & 5.7 \\
\hline \multicolumn{4}{|l|}{ Sexual orientation } \\
\hline Heterosexual & 63.4 & 50.6 & 55.5 \\
\hline Undisclosed/Unknown & 36.6 & 49.4 & 44.5 \\
\hline \multicolumn{4}{|l|}{ Virginity } \\
\hline Virgin & 2.0 & 0.6 & 1.1 \\
\hline Non-virgin & 25.7 & 30.2 & 28.5 \\
\hline Undisclosed/Unknown & 72.3 & 69.1 & 70.3 \\
\hline \multicolumn{4}{|l|}{ Nudity } \\
\hline No nudity & 78.2 & 80.2 & 79.5 \\
\hline Partial nudity & 14.9 & 13.6 & 14.1 \\
\hline Full nudity & 6.9 & 6.2 & 6.5 \\
\hline \multicolumn{4}{|l|}{ Sexual behavior } \\
\hline None & 63.4 & 69.1 & 66.9 \\
\hline Implied, not depicted & 4.0 & 11.1 & 8.4 \\
\hline Only kisses & 12.9 & 8.0 & 9.9 \\
\hline Mild & 12.9 & 1.9 & 6.1 \\
\hline Significant & 6.9 & 9.9 & 8.7 \\
\hline \multicolumn{4}{|l|}{ Agentic behavior } \\
\hline Fight & 9.9 & 23.5 & 18.3 \\
\hline Flight & 20.8 & 21.6 & 21.3 \\
\hline Freeze & 66.3 & 54.3 & 58.9 \\
\hline Other & 3.0 & 0.6 & 1.5 \\
\hline
\end{tabular}


Table 5 (continued)

\begin{tabular}{lccc}
\hline & Original & New version & Total \\
\hline Profanity & 13.9 & 39.5 & 29.7 \\
Drug consumption & 4.0 & 6.2 & 5.3 \\
Alcohol consumption & 33.7 & 21.0 & 25.9 \\
Total & 101 & 162 & 263 \\
\hline
\end{tabular}

Asian university student, accompanies the final girl until she is murdered. The 2009 version of Friday the 13th is also interesting. The Asian Chewie and the Afro-American Lawrence, two secondary characters mixed up in drugs and alcohol and whose deaths are even related, can be understood as the storyline's comic counterweights.

On a different note, regarding the partner relationships of the victims, there are no statistically significant differences between the original and the new films, although it is true that in both of them there is a tendency not to delve into this aspect. Similarly, their sexual orientation and whether or not they are virgins are subjects that are not usually broached. With respect to the first case, although the majority of the victims are understood as being heterosexual (versus no specific case of an LGTBI victim), most of the time their sexual orientation is not specified. As to virginity, another aspect that is not normally addressed, the final girl in the two versions of Black Christmas is a noteworthy case, for while Jess is pregnant in the 1974 original, there is an obscure allusion to the sexual relations between Kelli and her boyfriend during an argument in the 2006 remake. In this respect, it is interesting that when this variable is crossed with whether or not the victim dies, although there are no significant statistical differences in the original films, this is not the case in their new versions $\left(\mathrm{X}_{(2)}^{2}=6.830 ; p<0.04\right)$, thus indicating that the fact of being a virgin does not increase the chances of becoming a victim in the first slashers, but does indeed in their most recent adaptations. This finding should, nonetheless, be treated with caution, in particular when bearing in mind that only one character-Ellie in Sorority Row - was coded as an avowed virgin, while avoiding those cases in which the final girl is represented as sexually unavailable, as would be the case of Laurie Strode from Halloween, at least if her behavior is compared with that of her friends.

There are also differences depending on whether the character is male or female, although only in the new versions, with respect to sexual orientation $\left(\mathrm{X}^{2}{ }_{(2)}=9.015\right.$; $p<0.02)$ and virginity, or at least the declaration of it $\left(\mathrm{X}_{(3)}^{2}=9.020 ; p<0.03\right)$. Thus, these new films show an increase in the number of women known to be heterosexual and to have lost their virginity. In any case, what is more relevant is the fact that, although in both versions women present a greater nudity than men, it is exclusively in the recent films where significant differences are observed $\left(\mathrm{X}^{2}{ }_{(2)}=9.997 ; p\right.$ $<0.01)$. This figure means that, in the new films, it is statistically demonstrated that women appear more times naked than men, compared to the original ones.

Apropos the characters' agentic behavior, there are indeed significant statistical differences between the two types of films $\left(\mathrm{X}_{(3)}{ }=10.072 ; p<0.02\right)$, there being a higher number of victims who decide to confront the killers in the new versions. 
Likewise, as to this defensive behavior and whether or not the victims die on screen, there are statistically significant differences in both the original films $\left(\mathrm{X}_{(3)}^{2}=\right.$ $30.631 ; p<0.001)$ and in their new versions $\left(\mathrm{X}_{(3)}^{2}=42.096 ; p<0.001\right)$. As is only to be expected, to have a chance of survival it is better to fight or flee than to freeze.

With respect to this growing trend to fight in order to safeguard life, the case of Black Christmas is worth noting. Thus, as opposed to the first version in which the victims tend to stay frozen, the proactivity of the final girl in the new version, even when she is injured in the hospital, is definitive for her salvation.

On the other hand, in The Hills Have Eyes, although Brenda, the final girl, plays an active role in both versions when it comes to ending the mutants, she becomes more belligerent, aggressive and even vengeful in the remake. In both films, it is the final girl who defeats Papa Jupiter. However, in the first film she does it as a desperate act, to save her brother from the claws of the monster_-in fact, she sticks an axe it in his back and it is the brother who finishes him off with the gun-, while in the second she sticks a pickaxe him in his head as a way of finishing off a villain who is already lying practically dead and whose movements are impeded.

On the subject of the use of profanity, there are statistically significant differences between both types of films $\left(\mathrm{X}^{2}{ }_{(1)}=19.612 ; p<0.001\right)$, this being more profuse in the new versions. As to the victims' drug and alcohol consumption, abstinence is basically the rule, alcohol consumption even having dropped substantially-but not that of drugs - in the contemporary films with respect to the originals $\left(\mathrm{X}_{(1)}^{2}=\right.$ 5.214; $p<0.03$ ). In any event, there are no statistically significant differences in any of the films as regards the use of profanity and/or the consumption of drugs or alcohol and the chances of dying. Nonetheless, there are indeed plenty of caveats about excessive alcohol consumption in the new versions. In the remake of Prom Night, Michael, before being murdered, is clearly drunk when he treats his girlfriend Claire in a controlling and possessive way. Whereas in the new version of Sorority Row all the dramatic tension culminates in a practical joke that the girls are preparing in a fun context that begins with them all drinking shots.

\section{Characteristics of the Killers}

A total of 37 killers were identified, 18 in the original films and 19 in their new versions. There are no statistically significant differences in the aspects analyzed between both types of films. Broadly speaking, the profile is still that of a young or middle-aged white male adult who does not usually engage in any type sexual activity on screen_-except for the examples mentioned above_— and does not consume either drugs or alcohol (Table 6). As a matter of fact, as to sex, the only female killer is Pamela Voorhees in both versions of Friday the 13th, while the character of Agnes is introduced in the new version of Black Christmas.

Nevertheless, both in the original films and in the new versions, the killer is usually a figure unconnected to the protagonists, but there are also cases in which they are people close to the final girl (i.e., her brother in the original version of Prom Night, and her boyfriend in the first version of My Bloody Valentine and the remake of Sorority Row). In addition, there are three cases in which the killer is the 
Table 6 Characteristics of the killers (\%)

\begin{tabular}{|c|c|c|c|}
\hline & Original & New version & Total \\
\hline \multicolumn{4}{|l|}{ Gender } \\
\hline Female & 5.6 & 10.5 & 8.1 \\
\hline Male & 94.4 & 89.5 & 91.9 \\
\hline \multicolumn{4}{|l|}{ Age* } \\
\hline Child & 5.56 & 5.26 & 5.41 \\
\hline Adolescent & 5.56 & 0.00 & 2.70 \\
\hline Young adult & 44.44 & 47.37 & 45.95 \\
\hline Middle age & 44.44 & 52.63 & 48.65 \\
\hline Older adult & 5.56 & 0.00 & 2.70 \\
\hline \multicolumn{4}{|l|}{ Race } \\
\hline Undisclosed & 5.6 & 5.3 & 2.7 \\
\hline White & 94.4 & 94.7 & 48.6 \\
\hline \multicolumn{4}{|l|}{ Socioeconomic class } \\
\hline Low class/Redneck & 27.8 & 36.8 & 32.4 \\
\hline Middle class/Blue collar & 22.2 & 42.1 & 32.4 \\
\hline Middle-high class/White collar & 27.8 & 10.5 & 18.9 \\
\hline High class & 5.6 & 0.0 & 2.7 \\
\hline Undisclosed & 16.7 & 10.5 & 13.5 \\
\hline \multicolumn{4}{|l|}{ Relationship status } \\
\hline Undisclosed/unknown & 44.4 & 52.6 & 48.6 \\
\hline Single & 44.4 & 42.1 & 43.2 \\
\hline Serious partner & 11.1 & 5.3 & 8.1 \\
\hline \multicolumn{4}{|l|}{ Sexual orientation } \\
\hline Undisclosed/Unknown & 61.1 & 63.2 & 62.2 \\
\hline Heterosexual & 38.9 & 36.8 & 37.8 \\
\hline \multicolumn{4}{|l|}{ Virginity } \\
\hline Undisclosed/Unknown & 61.1 & 78.9 & 70.3 \\
\hline Virgin & 11.1 & 0.0 & 5.4 \\
\hline Non virgin & 27.8 & 21.1 & 24.3 \\
\hline \multicolumn{4}{|l|}{ Sexual behavior } \\
\hline None & 72.2 & 63.2 & 67.6 \\
\hline Implied, not depicted & 16.7 & 21.1 & 18.9 \\
\hline Mild & 5.6 & 10.5 & 8.1 \\
\hline Significant & 5.6 & 5.3 & 5.4 \\
\hline Drug consumption & 5.6 & 15.8 & 10.8 \\
\hline Alcohol consumption & 16.7 & 10.5 & 13.5 \\
\hline Total & 18 & 19 & 37 \\
\hline
\end{tabular}

*The sum of ages is not equal to $100 \%$ because of Michael Myers who appears (and kills) both as a child and as an adult 
protagonist of the film himself. But, although in the two films of Maniac it happens because they delve into the acts and secrets of the murderer, in the new version of My Bloody Valentine that is used as a surprise factor, to the point that the revelation serves as an anagnorisis for the disturbed protagonist.

\section{Death Analysis}

In the main, as with the number of victims, there are more deaths in the contemporary films. Of the 250 deaths analyzed, 153 occur in the new versions, with a more notable increase in those depicted on screen and statistically significant differences $\left(\mathrm{X}^{2}(1)=4.696 ; p<0.04\right)$.

Regarding the increase of violent scenes, there are evident examples in which the exact same scene is replicated but the death happens off-screen (original) or onscreen (remake). For example, in the penultimate climactic sequence of both versions of The Hitcher, the killer separates the victim's body in half by accelerating his truck. However, just as in the first version the situation is not shown and is resolved with a black fade, in the remake the viewer witnesses the disembowelment.

In relation to the weapons used to commit the murders, there are no statistically significant differences between the original films and their new versions. Practically two thirds of the murders are committed with blunt or sharp weapons, in keeping with the subgenre (Table 7), while the victims also meet their end by drowning, hanging or strangulation with a rope or similar object_—strangulation with the hands is relegated to female victims and associated with sexual moments, as in Maniac_ - being run over by some or other vehicle, dismembering in both versions of The Hitcher, and even by having their head crushed by a television, as is the case with Ismael Cruz in Rob Zombie's Halloween. On other occasions, however, the deaths are accidental, such as Mrs. Slater's in The House on Sorority Row. Additionally, firearms are sometimes employed to commit suicide, as in the new versions of The Texas Chainsaw Massacre and Halloween.

Lastly, as to the duration of these death scenes, the average is similar in the original films and in their new versions (Table 8$)$. In this sense, assuming equal variances $(F=$ $2.82, p>0.05)$, the null hypothesis of equal averages $\left(t_{(247)}=-1.13, p>0.05\right)$ cannot

Table 7 Murder weapons used and visualization of death (\%)

\begin{tabular}{llll}
\hline & Original & New version & Total \\
\hline Weapon & & & \\
Bladed weapon or projectiles & 63.92 & 66.01 & 65.20 \\
Guns & 9.28 & 8.50 & 8.80 \\
Hands & 3.09 & 7.84 & 6.00 \\
Others & 23.71 & 17.65 & 20.00 \\
Visualization of the death & & & \\
Death on screen & 60.82 & 73.86 & 68.80 \\
Death off screen & 39.18 & 26.14 & 31.20 \\
Total & 97 & 153 & 250 \\
\hline
\end{tabular}


Table 8 Average duration and standard deviation of the murders of women and men

\begin{tabular}{|c|c|c|c|c|c|c|}
\hline & \multicolumn{2}{|c|}{ Original } & \multicolumn{2}{|c|}{ New version } & \multicolumn{2}{|l|}{ Total } \\
\hline & $M$ & $S D$ & $M$ & $S D$ & $M$ & $S D$ \\
\hline Female & 19.48 & 22.20 & 22.95 & 32.28 & 21.44 & 28.28 \\
\hline Male & 23.00 & 46.93 & 26.81 & 49.67 & 25.41 & 48.55 \\
\hline Total & 21.33 & 37.16 & 25.24 & 43.38 & 23.69 & 41.00 \\
\hline
\end{tabular}

be ruled out. Similarly, nor are there any statistically significant differences in relation to the victims' sex. In both the original films and their new versions, no distinction is made, in quantitative terms, between killing a man or a woman in connection with the weapon used, whether this occurs on or off screen or the scene's duration. Nevertheless, it is interesting to make a more in-depth analysis of those scenes in which at least two people of different sexes die consecutively. This is the case, for example, of the couple formed by Lynda and Bob, who die in a similar way in both versions of Halloween: after having sex, Bob leaves the room until he is surprised by Michael Myers who kills him by nailing him to the wall with a knife. Then Myers, disguised as a ghost (with a sheet and glasses on top), ends up killing Lynda from behind, while she is left in front of the camera with her chest half uncovered in the first one, and totally naked in the second one. However, the real novelty in Rob Zombie's remake is that this double murder seems to be replicated shortly afterwards with the young couple formed by Annie and Paul_ _ in the original version Annie was murdered in her car. Both are intimating when they are surprised by Michael Myers, but while he eliminates him in a few seconds, he just hits her, who is always bare-chested, allowing her to crawl in the hope of escaping until the killer drags her across the floor by grabbing her by the foot, leaving her alive, but bloody and suffering, at the entrance of the house as a sort of claim for Laurie.

In this respect, as a general rule, the boy not only dies faster, but he dies first, thus avoiding the suffering of seeing his lover killed, which does happen with girls. This is also what happens at the beginning of the first version of Friday the 13th in which, with a totally subjective point of view by which the viewer adopts the gaze of the murderer, we do see her screaming with suffering, until the image is frozen with a close-up of the young woman's face screaming in despair. In the remake, Whitney and Mike are investigating a cabin when they are surprised by Jason appearing through the floor. He is dragged downstairs, and yet the camera decides to follow the girl who runs away to where they have camped to discover that another of her companions has his leg caught in a trap. Jason chases after her, but once he gets to her, he decides to hit the other male character over the head with his machete, while she screams and tries to run away. 


\section{Discussion and Conclusions}

In this study, we have performed a comparative content analysis on 13 original slasher films and their respective remakes with a view to establishing whether or not there are any differences between them in order to gain further insights into how the subgenre has evolved over time.

From a general perspective, we have observed a significant increase in the number of violent scenes, victims and deaths in the new versions with respect to the originals. These higher doses of explicit on screen violence can be linked to the entertainment aesthetics of recent audiovisual content as a whole (Darley, 2000; Isaacs, 2008), leading to the audience's progressive emotional desensitization to violent content (Brockmyer, 2013; Scharrer, 2008). Over the years, audiences have become accustomed to constant impact and stimulation or, in other words, to speed, excessive violence and shock (Calabrese, 1994), in all likelihood due to the proliferation of violent and gruesome scenes in films.

As regards the victims, corroborating the content analyses performed by Cowan and O'Brien (1990) and Weaver III (1991), there are no statistically significant differences in terms of their gender either in the original films or in their new versions. Nor for that matter are there any statistically significant differences in how the deaths are represented, whether they occur on or off screen, the death scenes' duration or the weapon used. So, although it is possible to observe a slight increase in male deaths in the new versions_- which is also related to the increase in adult deaths_- this can be interpreted as a logical progression in the number of deaths occurring in them. Nevertheless, an in-depth analysis reveals that, although there are no quantitative differences, there is a qualitative distinction in the instigation of male and female victims, supporting the findings of Clover (2015), Kvaran (2016), Trencansky (2001) or Weaver et al. (2015).

Indeed, it is possible to contend that the "male gaze" still prevails in the participation of the killers in the scenes, precisely because of the continuity between the originals and the new versions, for the stalking male killer with quasi-supernatural powers continues to be hegemonic and omnipresent, maintaining the characteristics with which he has been traditionally attributed in the subgenre. This male gaze holds even when the killers are women, as Friday the 13th's Pamela Voorhees and Black Christmas' Agnes, who do not have a normative female appearance in the traditional way. At this point, it is also noteworthy that, despite the technological advances between film versions, neither the killers nor the victims rarely make use of modern video surveillance devices in the remakes, as they do in other contemporary horror films (Waters, 2020), increasing the sense of continuity.

In this regard, from a purely sexual perspective, there is a clear difference between the role of men and women in the subgenre. He is the sexual aggressor, while she is the one who suffers the sexual abuse. This is something that is maintained in both versions of the films, with the difference that while in the original films the mere possession of the female body is pursued as if it were a man's right, in the remakes there is a greater focus on the process of explicit harassment and rape. 
In short, the woman's body is portrayed as an object of desire in these films, preserving her role as the killer's favorite victim from a qualitative perspective, regardless of whether the frequency of the deaths or the duration of the deaths, from a statistical perspective, remains equal between male and female characters. As has been proven, when the killer must confront victims of different sex, he chooses to end the man's life first, which in turn increases the suffering of the woman, who not only sees her partner/friend die, but must remain alert to the imminent attack on her person. This, which at times can be justified as a way for the killer to end the greatest threat, as men are supposed to have more strength and predisposition to struggle, loses its meaning in those cases in which the man is impeded in his movements, in opposition to the woman's freedom of movement. In fact, in many of these murders of male characters, the camera does not focus on the mortal victim, but instead looks at the girl's face, gloating over her suffering. Moreover, the early death of the male character in these scenes would imply that the female character suffers both from the death she witnesses and from the guilt of not having saved her fellow man, or even contribute to his murder, especially if this is the final girl, who is destined to end the monster.

All these messages linked to the male gaze, apart from creating a dangerous link between violence and sex, reaffirm the premise that male pleasure continues to drive the subgenre's films, as most of them are still directed and consumed by men, as Wellman et al. (2021, p. 674) highlight. At this point, the intrinsic connection between production context and the topic should be emphasized, since "the political implications of the Final Girl for feminism deserve closer examination" (Paszkiewicz and Rusnak 2020, p. 10). From a contextual perspective, it should be noted that none of the remakes analyzed coincide temporally with the fourth-wave feminism, a contextual reason why perhaps they do not show reflections on gender and on the trope of the final girl from a novel perspective as other more recent horror films like It Follows (David Robert Mitchell, 2015) do (Rusnak, 2020, p. 129). Therefore, there is no deconstruction of the final girl stereotype, since these productions design the heroine model according to their specific historical and ideological moment: the final girls of the remakes are designed from the emptiness of post-feminist "girl power", in the same way that the original survivors are politically correct designed according to the ideological conservatism that ends up defining them as "Reaganomics girls" (Pagnoni Berns, Rodríguez Fontao and Zárate, 2019, p. 86).

Even so, with respect to the victims' reactions, there is a clear increase in those who react more diligently and effectively to the killer's onslaught. On the one hand, this can be observed in a greater development of the concept of heroism, for the characters react more courageously than in the original films. On the other hand, in the logical evolution of audiences who are not now as innocent as they were when the classic slasher films were released, being perfectly familiar with the defining traits of the subgenre and aware of what is going to happen if the characters do not mend their ways. Thus, even though the subgenre's clichés are still resorted to (isolated places, characters who are left on their own, etc.), the characters' proactivity in the new versions is closely related to that of experienced audiences. This active defense is especially important in the case of the final girls and boys who, by and large, are no different from the rest of the victims 
in terms of their appearance or behavior, even as regards whether or not they are virgins, for this information is rarely provided. Indeed, it is particularly striking that it is precisely the new versions that seem to place greater importance on this aspect, with statistically significant differences between being or not being a virgin and dying in or surviving the bloodbath in these films.

Slasher films have been traditionally understood as cautionary tales, warning youngsters about the dangers of straying from the path of righteousness and, in this sense, they are the ones who, if they behave badly or mix with those who flout the moral rules of society, have to save themselves. This violation of the rules of conduct is related to premarital sex, to drug and alcohol consumption and even to the use of profanity. In this respect, there is a notable difference in the amount of alcohol consumed in the different versions, this being more moderate in the contemporary films, perhaps due to the "normalization" of consumption in current leisure and entertainment contexts, understood in terms of socialacceptance, so it would become less of a punishable action. Nonetheless, alcohol consumption continues to have negative consequences including accidents and boorish behavior.

In sum, going back to the research question- - Has the slasher subgenre evolved in terms of the use of violence and sex and the characteristics of the characters involved?_- it can be concluded that, although there is a sensation of continuity between the originals and their new versions, especially in statistical terms, the latter seem to see their burden of violence and sex increased, affecting the suffering of the female characters. In this sense, the reason for the increase in the number of male, older and other racial victims in the new films seems to rely on an interest in increasing the death toll and diversifying the nature of the characters, but lacking any relevance to the true course of the story. Finally, while certain clichés attributed to slasher films are refuted in light of the results, others have been rejected only in the case of the original versions, which would impact on the idea that the subgenre has become self-conscious over the years, taking advantage of the commonplaces traditionally attributed to slasher films.

Therefore, beyond this self-conscious continuity, which even magnifies certain characteristics not so exploited in the original films, it is important to ask, once we have seen the correspondences between the versions, to what extent the role attributed to these films as moralizing tales and reflection of the hopelessness of the young people of the 1970 and 1980s (Kvaran, 2016) is still valid in the new versions. In this regard, future research should inquire into reception studies that offer insight into the target audience's reaction and interpretation of these films. Likewise, it should be taken into account that the remakes analyzed temporally reached up to Obama's first term, so future studies, and this should also be understood as a limitation of the present one, should study the new versions of the classic films of the subgenre released, particularly, in the context of the Donald Trump era and the fourth feminist wave.

Acknowledgements The authors would like to express their gratitude to Dr. María del Mar RubioHernández for the recommendations and comments. 
Author's Contribution All authors contributed to the study conception and design. Material preparation and data collection and analysis were performed by Víctor Hernández-Santaolalla and Irene Raya. The manuscript was written by all authors.

Funding Open Access funding provided thanks to the CRUE-CSIC agreement with Springer Nature. The authors did not receive support from any organization for the submitted work.

Availability of Data and Material The collected data can be consulted by contacting the authors.

Code Availability All data were analyzed using the IBM SPSS Statistics 25.

\section{Declarations}

Conflict of interest The authors have no conflicts of interest to declare that are relevant to the content of this article.

Open Access This article is licensed under a Creative Commons Attribution 4.0 International License, which permits use, sharing, adaptation, distribution and reproduction in any medium or format, as long as you give appropriate credit to the original author(s) and the source, provide a link to the Creative Commons licence, and indicate if changes were made. The images or other third party material in this article are included in the article's Creative Commons licence, unless indicated otherwise in a credit line to the material. If material is not included in the article's Creative Commons licence and your intended use is not permitted by statutory regulation or exceeds the permitted use, you will need to obtain permission directly from the copyright holder. To view a copy of this licence, visit http://creativecommons.org/licen ses/by/4.0/.

\section{References}

Berliner, T. (2001). The pleasures of disappointment: Sequels and The Godfather, Part II. Journal of Popular Film and Video, 53(2\&3), 107-123.

Brockmyer, J. F. (2013). Media violence, desensitization, and psychological engagement. In Dill, K. E. (Ed.), The Oxford handbook of media psychology (pp. 212-222). Oxford: Oxford University Press.

Calabrese, O. (1994). La era neobarroca. Madrid: Cátedra.

Christensen, K. (2016). "Look what you did to me!": (Anti)Feminism and extratextuality in the remake of A Nightmare on Elm Street (2010). Journal of Film and Video, 68(2), 29-45. https://doi.org/10.5406/ jfilmvideo.68.2.0029.

Clayton, W. (2015). Introduction. The collection awakes. In Clayton, W. (Ed.), Style and form in the Hollywood Slasher Film (pp. 1-14). Basingstoke: Palgrave Macmillan.

Clayton, W. (2020). See! Hear! Cut! Kill! Experiencing Friday the 13th. Jackson: University Press of Mississippi.

Clover, C. J. (2015). Men, women and chainsaws. Gender in the modern horror film. Princeton: Princeton University Press.

Connelly, K. (2007). Defeating the male monster in Halloween and Halloween H20. Journal of Popular Film and Television, 35(1), 12-21. https://doi.org/10.3200/JPFT.35.1.12-21.

Cowan, G., \& O'Brien, M. (1990). Gender and survival vs. death in slasher films: A content analysis. Sex Roles, 23, 187-196. https://doi.org/10.1007/BF00289865.

Darley, A. (2000). Visual digital culture. Surface play and spectacle in new media genres. London: Routledge.

Durham, C. A. (1998). Double takes. Culture and gender in French films and their American remakes. Hanover: University Press of New England.

Fernández Labayen, M., \& Martín Morán, A. (2017). Remakes transnacionales: dinámicas industriales y estéticas. Fonseca, Journal of Communication, 14, 59-73. https://doi.org/10.14201/fjc2017145973. 
Forman-Brunell, M. (2002). Maternity, murder, and monsters: Legends of babysitter horror. In Gateward, F., \& Pomerance, M. (Eds.), Sugar, spice, and everything nice. Cinemas of girlhood (pp. 253-267). Detroit: Wayne State University Press.

Genette, G. (1997). Palimpsests. Literature in the Second Degree. Lincoln and London: University of Nebraska Press.

Gilpatric, K. (2010). Violent female action characters in contemporary American cinema. Sex Roles, 62, 734-746. https://doi.org/10.1007/s11199-010-9757-7.

Greenberg, H. R. (1991). Raiders of the lost text: Remaking as contested homage in always. Journal of Popular Film and Television, 18(4), 164-171. https://doi.org/10.1080/01956051.1991.10662030.

Hernández-Santaolalla, V. (2019). Final girls and female serial killers: A review of the slasher television series from a gender perspective. In Gerrard, S., Holland, S., \& Shail, R. (Eds.), Gender and contemporary horror in television (pp. 83-94). Bingley: Emerald Publishing Limited.

Isaacs, B. (2008). Toward a new film aesthetic. New York: Continuum.

Jess-Cooke, C., \& Verevis, C. (2010). Second takes: Critical approaches to the film sequel. Albany: State University of New York Press.

Keisner, J. (2008). Do you want to watch? A study of the visual rhetoric of the postmodern horror film. Women's Studies, 37(4), 411-427. https://doi.org/10.1080/00497870802050019.

Krippendorff, K. (2004). Content analysis. Thousand Oaks: Sage.

Kvaran, K. M. (2016). "You're all doomed!" A socioeconomic analysis of slasher films. Journal of American Studies, 50(4), 953-970. https://doi.org/10.1017/S0021875815002674.

Lizardi, R. (2010). Re-imagining hegemony and misogyny in the contemporary slasher remake. Journal of Popular Film and Television, 38(3), 113-121. https://doi.org/10.1080/01956051003623464.

McKee, R. (2010). Story: Style, structure, substance, and the principles of screenwriting. New York: HarperCollins.

Moine, R. (2007). Remakes. Les films francais à Hollywood. Paris: CNRS Editions.

Molitor, F., \& Sapolsky, B. S. (1993). Sex, violence, and victimization in slasher films. Journal of Broadcasting \& Electronic Media, 37(2), 233-242. https://doi.org/10.1080/08838159309364218.

Mulvey, L. (1999). Visual pleasure and narrative cinema. In Braudy, L., \& Cohen, M. (Eds.), Film theory and criticism: Introductory readings (pp. 833-844). Oxford: Oxford University Press.

Nelson, A. P. (2010). Traumatic childhood now included. Todorov's fantastic and the uncanny slasher remake. In Hantke, S. (Ed.), American horror film: The genre at the turn of the millennium (pp. 103-118). Jackson: University Press of Mississippi.

Pagnoni Berns, F. G., Rodríguez Fontao, C. A., \& Zárate, M. S. (2019). From traditional slasher to fourth wave. Fantastical reconversion in The Final Girl and Happy Death Day. In Frankel, V. E. (Ed.), Fourth Wave Feminism in Science Fiction and Fantasy. Volume 1. Essays on Film Representations, 2012-2019 (pp. 77-87). Jefferson: McFarland \& Company, Inc.

Paszkiewicz, K., \& Stacy, R. (2020). Introduction: Reimagining the final girl in the twenty-first century. In Paszkiewicz, K., \& Rusnak, S. (Eds.), Final girls, feminism and popular culture (pp. 1-37). London: Palgrave Macmillan.

Pérez Ochando, L. (2016). Todos los jóvenes van a morir. Ideología y rito en el slasher film. Murcia: Micromegas.

Petridis, S. (2014). A historical approach to the slasher film. Film International, 12(1), 76-84. https://doi. org/10.1386/fiin.12.1.76_1.

Quaresima, L. (2002). Loving texts two at a time: The film remake. CiNéMAS. Revue d'études cinématographiques, 12(3), 73-84.

Rockoff, A. (2002). Going to pieces. The rise and fall of the slasher film, 1978-1986. Jefferson: McFarland \& Company, Inc.

Rubin, M. (2000). Thrillers. Cambridge: Cambridge University Press.

Rusnak, S. (2020). The slasher film and the final girl get makeovers: It Follows and the politics of fourth wave feminism. In Paszkiewicz, K., \& Rusnak, S. (Eds.), Final girls, feminism and popular culture (pp. 115-133). London: Palgrave Macmillan.

Ryan, M., \& Kellner, D. (1988). Camera politica: The politics and ideology of contemporary hollywood films. Bloomington: Indiana University Press.

Scharrer, E. (2008). Media exposure and sensitivity to violence in news reports: Evidence of desensitization? Journalism \& Mass Communication Quarterly, 85(2), 291-310. https://doi.org/10.1177/10776 9900808500205.

Stam, R. (2000). Film theory. An introduction. Malden: Blackwell. 
Trencansky, S. (2001). Final Girls and terrible youth: Transgression in 1980s slasher horror. Journal of Popular Film and Television, 29(2), 63-73. https://doi.org/10.1080/01956050109601010.

Verevis, C. (2006). Film remakes. Edinburgh: Edinburgh University Press.

Wagner, G. (1975). The novel and the cinema. London: Tantivy Press.

Waters, S. (2020). Surveillance, narrative, and spectatorship in recent American horror films. In Pascuzzi, F., \& Waters, S. (Eds.), The spaces and places of horror (pp. 41-54). Wilmington: Vernon Press.

Weaver, A. D., Ménard, A. D., Cabrera, C., \& Taylor, A. (2015). Embodying the moral code? Thirty years of final girls in slasher films. Psychology of Popular Media Culture, 4(1), 31-46. https://doi. org/10.1037/ppm0000006.

Weaver, J. B. III. (1991). Are "slasher" horror films sexually violent? A content analysis. Journal of Broadcasting \& Electronic Media, 35(3), 385-392. https://doi.org/10.1080/08838159109364133.

Wee, V. (2005). The Scream trilogy, "hyperpostmodernism," and the late-nineties teen slasher film. Journal of Film and Video, 57(3), 44-61.

Wee, V. (2006). Resurrecting and updating the teen slasher. The case of Scream. Journal of Popular Film \& Television, 34(2), 50-61. https://doi.org/10.3200/JPFT.34.2.50-61.

Wee, V. (2014). Introduction. The Horror, the Horror.... In Wee, V. (Ed.), Japanese horror films and their American remakes. Translating fear, adapting culture (pp. 1-28). London: Routledge.

Wellman, A., Meitl, M. B., \& Kinkade, P. (2021). Lady and the vamp: Roles, sexualization and brutalization of women in slasher films. Sexuality \& Culture, 25(2), 660-679. https://doi.org/10.1007/ s12119-020-09788-4

Welsh, A. (2009). Sex and violence in the slasher horror film: A content analysis of gender differences in the depiction of violence. Journal of Criminal Justice and Popular Culture, 16(1), 1-25.

Welsh, A. (2010). On the perils of living dangerously in the slasher horror film: Gender differences in the association between sexual activity and survival. Sex Roles, 62, 762-773. https://doi.org/10.1007/ s11199-010-9762-x.

Wetmore, K. J. (2012). Post-9/11 Horror in American Cinema. New York: Continuum.

Wood, R. (2003). Hollywood from Vietnam to Reagan... and Beyond. Expanded and Revised Edition. New York: Columbia University Press.

Publisher's Note Springer Nature remains neutral with regard to jurisdictional claims in published maps and institutional affiliations. 